\title{
Ultrasound-Assisted Rapid ZIF-8 Synthesis, Porous ZnO Preparation by Heating ZIF-8, and Their Photocatalytic Activity
}

\author{
Pham Dinh Du $\mathbb{D}^{1}{ }^{1}$ Nguyen Trung Hieu, ${ }^{1}$ and Tran Vinh Thien ${ }^{2}$ \\ ${ }^{1}$ Thu Dau Mot University, Binh Duong 75000, Vietnam \\ ${ }^{2}$ Ho Chi Minh City University of Natural Resources and Environment, HCM City 70000, Vietnam \\ Correspondence should be addressed to Pham Dinh Du; dupd@tdmu.edu.vn
}

Received 2 April 2021; Revised 11 May 2021; Accepted 11 June 2021; Published 2 July 2021

Academic Editor: Duy Trinh Nguyen

Copyright ( 2021 Pham Dinh Du et al. This is an open access article distributed under the Creative Commons Attribution License, which permits unrestricted use, distribution, and reproduction in any medium, provided the original work is properly cited.

Zeolitic imidazolate framework-8 (ZIF-8) is synthesized quickly at room temperature in methanol with the support of ultrasound. Porous $\mathrm{ZnO}$ is also prepared via the thermal treatment of ZIF-8. The photocatalytic activities of the obtained materials are demonstrated via methylene blue (MB) decomposition under UV radiation. The obtained materials are characterized by means of X-ray diffraction (XRD), Fourier-transform infrared spectroscopy (FT-IR), scanning electron microscopy (SEM), nitrogen adsorption/desorption isotherms, UV-Vis diffuse reflectance spectra (DR-UV-Vis), and photoluminescence spectra. The results indicate that ZIF- 8 and the materials obtained from ZIF-8 by heating in the air have photocatalytic activity under UV irradiation. The $\mathrm{ZnO}$ sample obtained by ZIF-8 calcination at $660^{\circ} \mathrm{C}$ for $5 \mathrm{~h}$ has the highest photocatalytic activity. However, the MB degradation photocatalytic efficiency of the $\mathrm{ZnO}$ samples is even lower than that of the ZIF-8 samples, indicating that ZIF-8 is an effective photocatalyst in the treatment of environmental pollution.

\section{Introduction}

Zeolitic imidazolate framework 8 (ZIF-8) is a hybrid material of zinc ions with 2-methylimidazole (denoted as meIm), forming crystals in the cubic space group I $\overline{4} 3 \mathrm{~m}(a=16.991$ Å) $[1,2]$. ZIF-8 crystals are usually synthesized in N,Ndimethylformamide and possess thermal stability from room temperature to $450^{\circ} \mathrm{C}$ and chemical stability in benzene, methanol, and water at boiling temperature for up to a week [1]. In addition, ZIF-8 has a large surface area $\left(S_{\mathrm{BET}}=1630\right.$ $\left.\mathrm{m}^{2} \cdot \mathrm{g}^{-1}\right)$ and a large porous volume $\left(0.636 \mathrm{~cm}^{3} \cdot \mathrm{g}^{-1}\right)$ [1].

ZIF-8 has been utilized as a heterogeneous catalyst for numerous reactions. In 2013, Wee et al. [3] employed zeolitic imidazolate framework- 8 as a catalyst for the esterification of oleic acid and glycerol. The synthesis of styrene carbonate from $\mathrm{CO}_{2}$ and styrene oxide with ZIF- 8 as a catalyst was also studied by Zhu et al. [4]. ZIF-8 was also an effective heterogeneous catalyst for ethyl methyl carbonate synthesis from dimethyl carbonate and diethyl carbonate [5]. In addition to catalyzing organic synthesis, ZIF- 8 was also used as a photocatalyst to decompose organic pollutants $[6,7]$. In
2014, Jing et al. [6] used ZIF-8 as a photocatalyst to decompose methylene blue. The authors also showed that ZIF-8 has higher photocatalytic activity than other materials. In addition, ZIF-8 is also used as a substrate to fabricate composites [8-16] or core-shell materials [17-20] with different elements to expand the applicability of this metal-organic framework material.

Zinc oxide $(\mathrm{ZnO})$ is an $n$-type semiconductor with a wide bandgap $(3.37 \mathrm{eV})$ and a large excitation binding energy (60 $\mathrm{meV}$ ) at room temperature [21-25]. This material has unique electrical and photovoltaic properties, so it has been studied and applied in the fields of photocatalysis, gas sensing, medicine, electrochemistry, and solar cells [21-24, 26-32] ZnO has extremely rich morphologies, depending on the synthesis method, such as spheres [27, 30], nanorods [28], nanowires [29], and flower-shaped nano [32].

Metal-organic frameworks (MOFs) are porous solid nanomaterials created from metal ions (or inorganic hybrid centers) linked to organic bridges. Besides the direct use, MOFs can be alternatively used as sacrificial templates/precursors for the preparation of a wide range of hybrid 


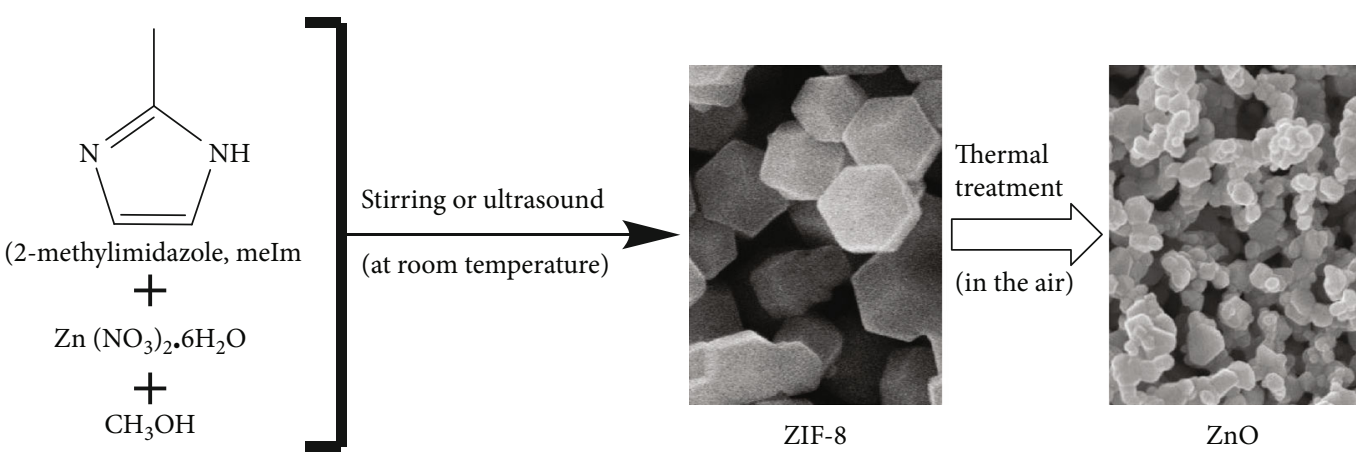

Scheme 1: Illustrative scheme of synthesis and thermal treatment of ZIF-8.

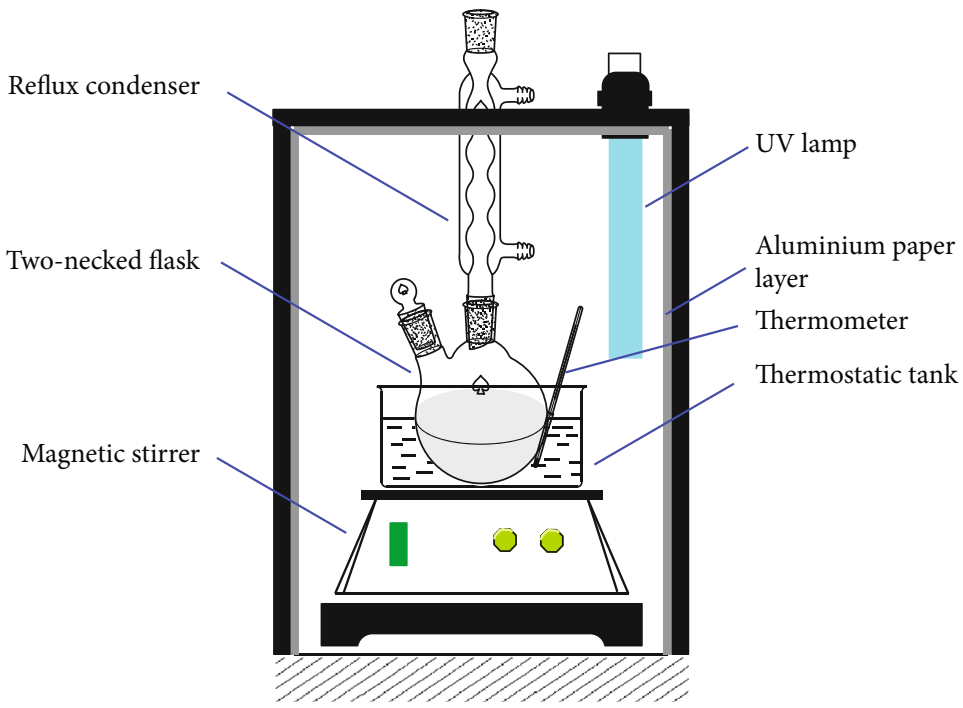

Scheme 2: Device model for photocatalytic survey of material samples to the degradation reaction of methylene blue in aqueous solution.

inorganic nanomaterials in straightforward and controllable manners [33]. ZIF-8 is a metal-organic framework material made up of $\mathrm{Zn}$ atoms linked to meIm, forming the formula $\mathrm{Zn}(\mathrm{meIm})_{2}$. Therefore, it is possible to create porous $\mathrm{ZnO}$ structures via the thermal treatment of the ZIF-8 material $[21,26]$. Yang et al. [34] indicated that the photocatalytic activity of the $\mathrm{ZnO} / \mathrm{ZIF}-8$ hybrid material was also improved, compared with ZIF-8.

Studies on ZIF-8 have become attractive after the work by Cravillon et al. [35], who reported the rapid synthesis of nanostructured ZIF-8 crystals at room temperature in the methanol solution of zinc (II) nitrate and meIm. After that, Bux et al. $[36,37]$ utilized other metal precursors in methanol and the coating method to successfully produce ZIF-8 films on titania and $\alpha$-alumina, McCarthy et al. [38] and Venna and Carreon [39] also synthesized ZIF-8 membrane in methanol at room temperature with $\alpha-\mathrm{Al}_{2} \mathrm{O}_{3}$ support. These materials could separate gases with higher hydrogen filtration from the mixture of $\mathrm{H}_{2} / \mathrm{N}_{2}, \mathrm{H}_{2} / \mathrm{CH}_{4}$, and $\mathrm{H}_{2} / \mathrm{C}_{3} \mathrm{H}_{8}$ [36-38] and collect carbon dioxide from the $\mathrm{CO}_{2} / \mathrm{CH}_{4}$ mixture [39]. Recently, ZIF-8 has been widely prepared by solvothermal method [1, 3], the microwave-assisted method [40, 41], the reverse microemulsion method [42], the room-temperature synthesis in methanol $[4,34,35]$, the room-temperature synthesis in water [43], the ultrasonic synthesis [12], etc. How-

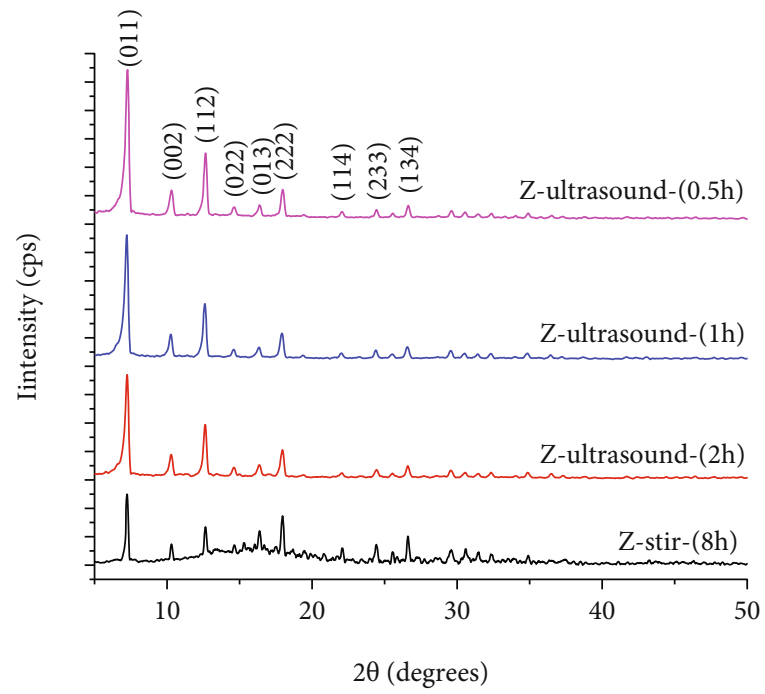

FIgURE 1: XRD patterns of Z-stir- $(8 \mathrm{~h})$ and ZIF-8 samples synthesized with a different treating time with ultrasound.

ever, the search for a simple synthesis method with short preparation time and energy saving is still attracting much attention of scientists. 


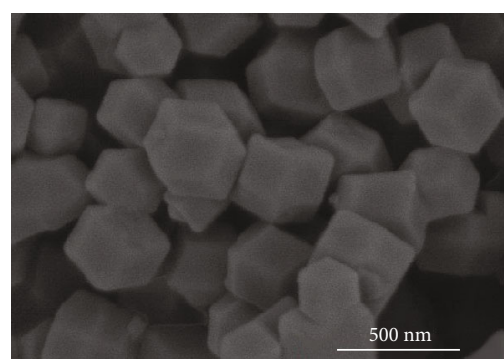

(a)

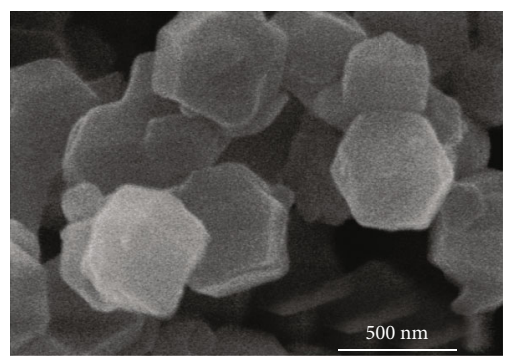

(c)

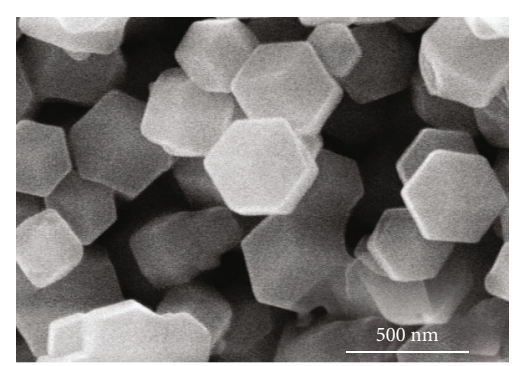

(b)

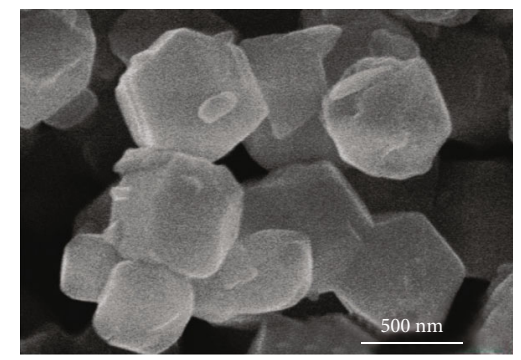

(d)

Figure 2: SEM images of ZIF-8 samples: (a) Z-stir-(8 h); (b) Z-ultrasound-(0.5 h); (c) Z-ultrasound-(1 h); (d) Z-ultrasound-(2 h).

In this paper, we present a rapid ultrasound-assisted method for synthesizing ZIF-8 in methanol and, therefore, the manufacture of porous $\mathrm{ZnO}$ by heating ZIF- 8 in the air (at temperature of 250,500 , or $660^{\circ} \mathrm{C}$ ). The photocatalytic activity of the obtained material is also assessed through methylene blue decomposition under UV radiation.

\section{Experimental}

2.1. Materials. Zinc nitrate hexahydrate $\left(\mathrm{Zn}\left(\mathrm{NO}_{3}\right)_{2} \cdot 6 \mathrm{H}_{2} \mathrm{O}\right.$, Fisher), 2-methylimidazole $\left(\mathrm{C}_{4} \mathrm{H}_{6} \mathrm{~N}_{2}, 99 \%\right.$, Acros) (denoted as meIm), methanol $\left(\mathrm{CH}_{3} \mathrm{OH}, 99.9 \%\right.$, Fisher) (denoted as $\mathrm{MeOH})$, and methylene blue $\left(\mathrm{C}_{16} \mathrm{H}_{18} \mathrm{ClN}_{3} \mathrm{~S}\right.$, Merck) (denoted as $\mathrm{MB}$ ) are used in this study.

2.2. Preparation of ZIF-8 and Porous $\mathrm{ZnO}$. The synthesis of ZIF-8 (Scheme 1) was carried out according to earlier reports with some modifications $[4,44]$. In a typical process, $8 \mathrm{mmol}$ of $\mathrm{Zn}\left(\mathrm{NO}_{3}\right)_{2} \cdot 6 \mathrm{H}_{2} \mathrm{O}$ was dissolved in $1.4 \mathrm{~mol}$ of $\mathrm{MeOH}$ (solutions 1), and $64.4 \mathrm{mmol}$ of meIm was dissolved in $1.4 \mathrm{~mol}$ of $\mathrm{MeOH}$ (solutions 2). Solution 2 was then added to solution 1, and the as-prepared mixture was stirred for $8 \mathrm{~h}$. Finally, the obtained ZIF-8 powder (denoted as Z-stir- $(8 \mathrm{~h})$ ) was collected by using centrifugation at $3000 \mathrm{rpm}$, washed three times with $\mathrm{MeOH}$, and dried overnight at $100^{\circ} \mathrm{C}$.

The influence of ultrasonic conditions on the structural forming efficiency of the ZIF-8 material was investigated by treating the mixture of solutions 1 and 2 with ultrasound for $0.5,1$, and $2 \mathrm{~h}$ (SONICS Vibra-cell ultrasound equipment). The samples were denoted as Z-ultrasound- $(0.5 \mathrm{~h})$, Z-ultrasound-( $1 \mathrm{~h})$, and Z-ultrasound-( $2 \mathrm{~h})$.

Zinc oxide $(\mathrm{ZnO})$ was obtained by heating ZIF- 8 in the air at different temperatures for a specified time (Scheme 1). The resulting $\mathrm{ZnO}$ samples were denoted as Z- $x$ - $(y \mathrm{~h})$, where $x$ is the treatment temperature $\left({ }^{\circ} \mathrm{C}\right)$ and $y$ is the treatment time $(\mathrm{h})$.

2.3. Material Characterization. X-ray diffraction (XRD) patterns were recorded on a VNU-D8 Advance Instrument (Bruker, Germany) under $\mathrm{Cu} \mathrm{K} \alpha$ radiation $(\lambda=1.5406 \AA)$. Scanning electron microscopy (SEM) images were obtained by using an SEM JMS-5300LV (Japan), and Fouriertransform infrared spectra (FT-IR) were recorded with a Jasco FT/IR-4600 spectrometer (Japan) in the range of $4000-400 \mathrm{~cm}^{-1}$. The $\mathrm{N}_{2}$ adsorption/desorption isotherm measurement test was performed at $77 \mathrm{~K}$ in a Tristar 3000 analyzer, and before setting the dry mass, the samples were degassed at $250^{\circ} \mathrm{C}$ with $\mathrm{N}_{2}$ for $5 \mathrm{~h}$. The thermal behavior of the samples was investigated by using thermal analysis on Labsys TG/dTG SETARAM. UV-Vis diffuse reflectance (DR-UV-Vis) data were collected over the spectral range 190-800 nm with a UV2600 Shimadzu (Japan) spectrophotometer equipped with an integrated sphere with $\mathrm{BaSO}_{4}$ as a reference. The photoluminescence (PL) spectra of the materials were recorded on a FluoroMax-4 (Horiba) at the $100 \mathrm{~nm}$ excitation wavelength.

2.4. Photocatalytic Activity Studies. The photocatalytic activity of ZIF-8 (or ZnO) samples was assessed through the photocatalytic degradation of $\mathrm{MB}$ under UV-C radiation (Philips TUV 16W T5 4P-SE, Poland) (Scheme 2). $0.05 \mathrm{~g}$ of the catalyst was added to $100 \mathrm{~mL}$ of $5 \mathrm{mg} \cdot \mathrm{L}^{-1} \mathrm{MB}$ solution in a 500 $\mathrm{mL}$ two-necked flask with a reflux condenser. Before irradiation, the suspension solution was stirred with a magnetic stirrer for $60 \mathrm{~min}$ to achieve adsorption-desorption equilibrium. During irradiation, the magnetic stirring was maintained to create a homogeneous suspension. After each determined period, $5 \mathrm{~mL}$ of solution was withdrawn, centrifuged to remove the catalyst, and the concentration of the remaining 


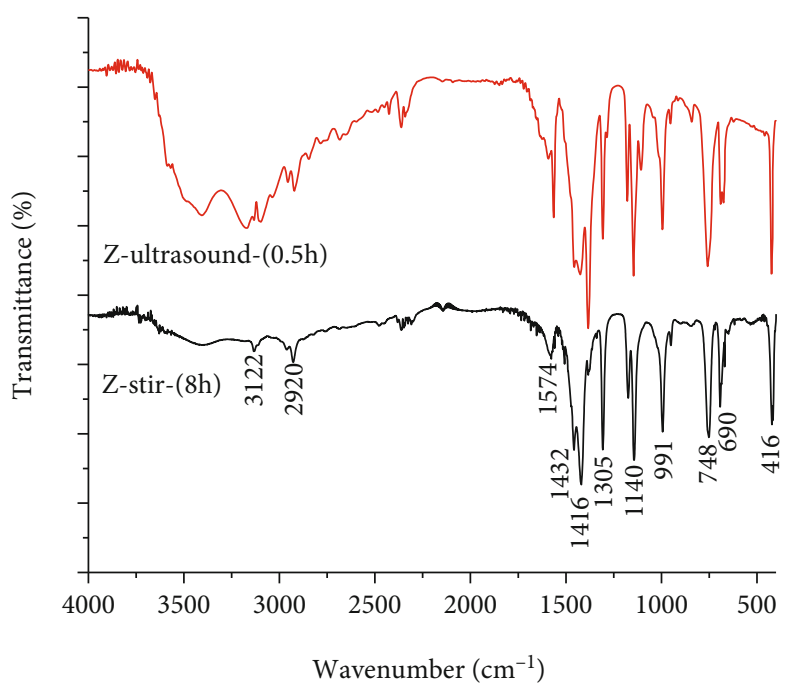

(a)

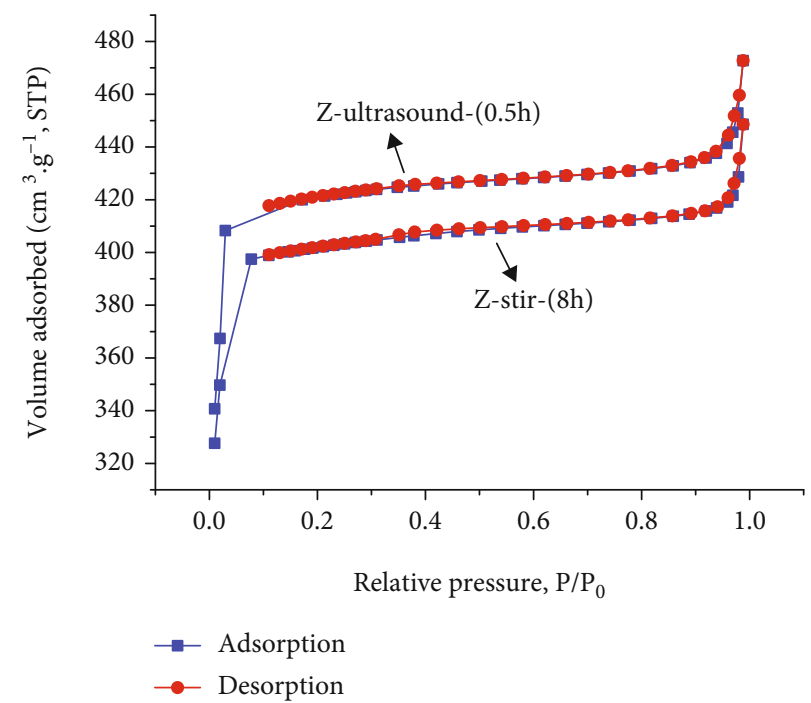

(b)

Figure 3: FT-IR spectrum (a) and nitrogen adsorption-desorption isotherms (b) of Z-stir-( $8 \mathrm{~h})$ and Z-ultrasound-(0.5 h).

TABLE 1: Porous properties of ZIF-8 samples.

\begin{tabular}{lcccc}
\hline Sample & $\begin{array}{c}\text { BET surface area } \\
\left(\mathrm{m}^{2} \cdot \mathrm{g}^{-1}\right)\end{array}$ & $\begin{array}{c}\boldsymbol{t} \text {-Plot micropore area } \\
\left(\mathrm{m}^{2} \cdot \mathrm{g}^{-1}\right)\end{array}$ & $\begin{array}{c}\boldsymbol{t} \text {-Plot external surface area } \\
\left(\mathrm{m}^{2} \cdot \mathrm{g}^{-1}\right)\end{array}$ & $\begin{array}{c}\boldsymbol{t} \text {-Plot micropore volume } \\
\left(\mathrm{cm}^{3} \cdot \mathrm{g}^{-1}\right)\end{array}$ \\
\hline Z-stir-(8 h) & 1279 & 1237 & 42 & 0.604 \\
Z-ultrasound-(0.5 h) & 1367 & 1324.5 & 42.5 & 0.633 \\
\hline
\end{tabular}

MB solution was determined with the UV-Vis method on a Jasco V-770 (Japan) at $\lambda_{\max }=664 \mathrm{~nm}$.

The degradation efficiency $D(\%)$ of $\mathrm{MB}$ was calculated according to the following equation:

$$
D(\%)=\frac{\left(C_{0}-C_{t}\right)}{C_{0}} \times 100,
$$

where $C_{t}$ is the concentration of $\mathrm{MB}$ in the solution at time $t$ and $C_{0}$ is the concentration of $\mathrm{MB}$ at the initial time.

\section{Results and Discussion}

3.1. Characterization of ZIF-8. Figure 1 shows the XRD patterns of the Z-stir- $(8 \mathrm{~h})$ and the ZIF- 8 samples synthesized with a different treatment time with ultrasound. The characteristic peaks of the ZIF-8 structure are similar to those reported in other work $[1,4,15,16,39,45-48]$. In particular, the diffraction peak (011) at $7.2^{\circ}$ has a high intensity, indicating that ZIF-8 is highly crystalline [48]. In addition, the samples synthesized under ultrasound have peaks with higher intensity and sharper shape than the Z-stir- $(8 \mathrm{~h})$ sample. This shows that ultrasound significantly contributes to the formation of crystals in the materials.

The morphology of the Z-stir- $(8 \mathrm{~h})$ and ZIF-8 samples synthesized with a different treatment time with ultrasound is very similar (Figure 2 ). They all include cubes or hexagons with edges of about $\sim 100 \mathrm{~nm}$. However, when the treatment time is 1 or $2 \mathrm{~h}$ (Figures 2(c) and 2(d)), the surface of the material is no longer smooth. Therefore, $0.5 \mathrm{~h}$ should be an appropriate treatment time with ultrasound for the synthesis of ZIF-8 with high crystallinity and homogeneous morphology.

The FT-IR spectra of Z-stir- $(8 \mathrm{~h})$ and Z-ultrasound- $(0.5$ h) samples are also similar to those reported on ZIF-8 [5, 10, 15, 47-49]. The peaks at 3122 and $2920 \mathrm{~cm}^{-1}$ correspond to the asymmetric stretching vibrations of aliphatic $\mathrm{C}-\mathrm{H}$ and in aromatic rings (Figure 3(a)). The absorption band at 1574 $\mathrm{cm}^{-1}$ is attributed to the stretching vibration of the $\mathrm{C}=\mathrm{N}$ bond, and the peaks at 1140 and $1305 \mathrm{~cm}^{-1}$ correspond to the bending signals of the imidazole ring. The peaks at 1416 and $1432 \mathrm{~cm}^{-1}$ are assigned to the stretching vibrations of the imidazole ring. Similarly, the peaks at 991 and $748 \mathrm{~cm}^{-1}$ can be attributed to the bending vibrations of $\mathrm{C}-\mathrm{N}$ and $\mathrm{C}$ $\mathrm{H}$. In addition, the peak at $690 \mathrm{~cm}^{-1}$ is an out-of-plane bending variation of the imidazole ring. The sharp absorption band at $416 \mathrm{~cm}^{-1}$ is generated by the stretching vibration of $\mathrm{Zn}-\mathrm{N}$, indicating that zinc atoms are bound to the nitrogen atoms in the 2-methylimidazolate bridges. These peaks indicate the presence of the ZIF-8 structure in all the material samples.

Figure 3(b) shows the nitrogen adsorption-desorption isotherms of the Z-stir- $(8 \mathrm{~h})$ and Z-ultrasound- $(0.5 \mathrm{~h})$ samples at $77 \mathrm{~K}$. According to the IUPAC classification, these 


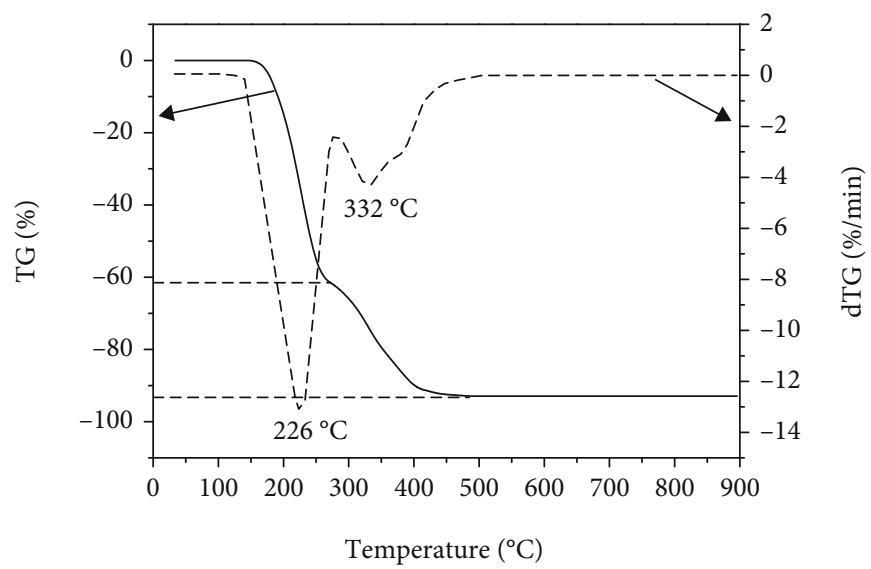

(a)

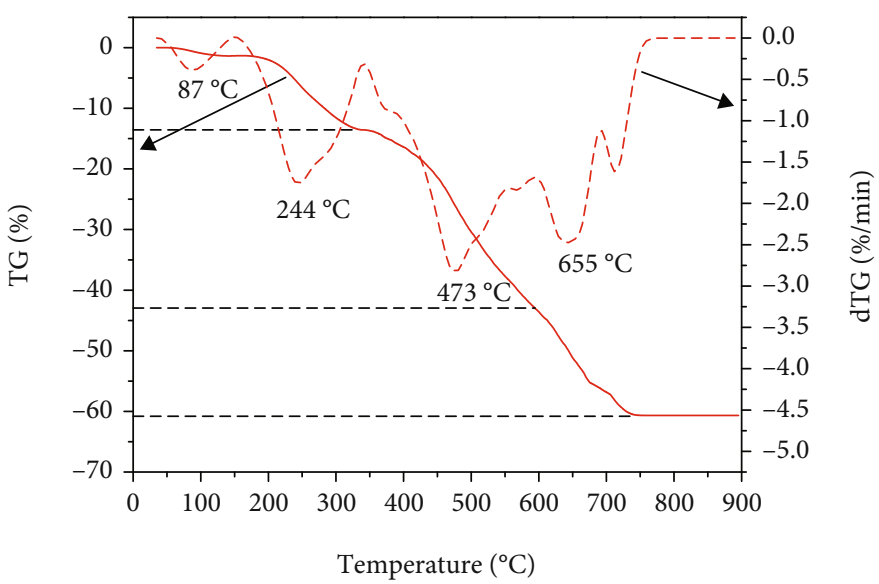

(b)

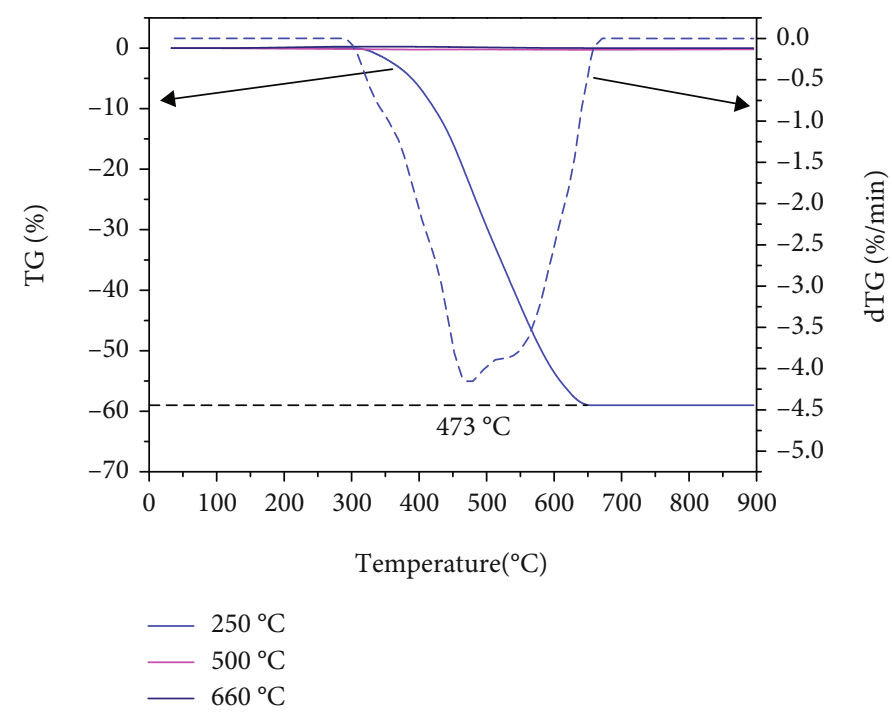

(c)

FIGURE 4: TG/dTG profiles: (a) meIm, (b) ZIF-8, and (c) Z-x-(3h) samples, where $x$ is the treatment temperature for ZIF- 8 samples $(x=250$, 500 , or $\left.660^{\circ} \mathrm{C}\right)$.

isotherms belong to type $\mathrm{I}$, indicating that these materials have porosity at a micron scale. The specific surface areas of the Z-stir- $(8 \mathrm{~h})$ and Z-ultrasound- $(0.5 \mathrm{~h})$ samples are $1279 \mathrm{~m}^{2} \cdot \mathrm{g}^{-1}$ and $1367 \mathrm{~m}^{2} \cdot \mathrm{g}^{-1}$, respectively (Table 1 ).
3.2. Characterization of $\mathrm{ZnO}$. Because the sample Z-ultrasound- $(0.5 \mathrm{~h})$ has a large surface area and high crystallinity, it was utilized to produce porous $\mathrm{ZnO}$. The thermal behavior of meIm, untreated ZIF-8, and heat-treated ZIF-8 at 250, 500, 


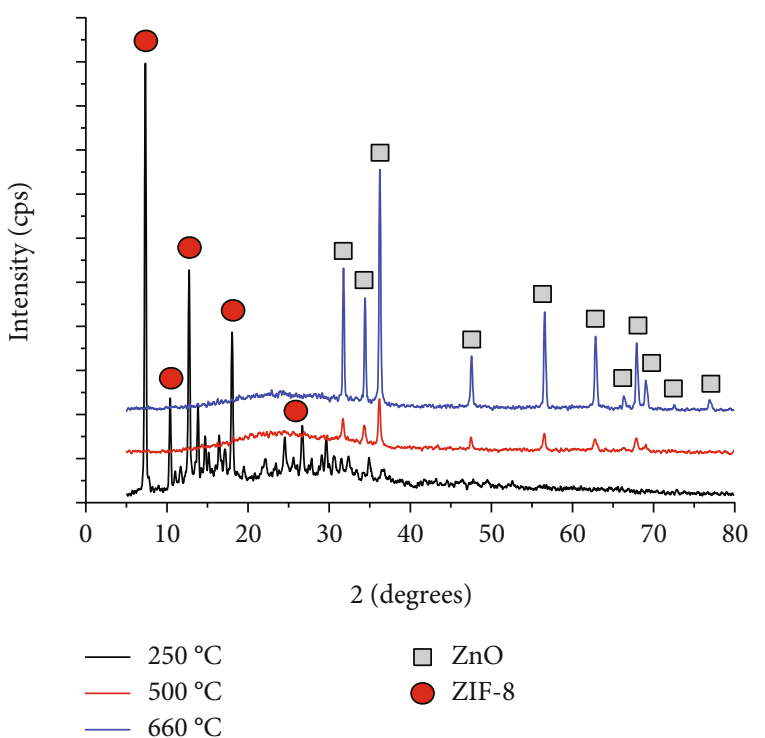

(a)

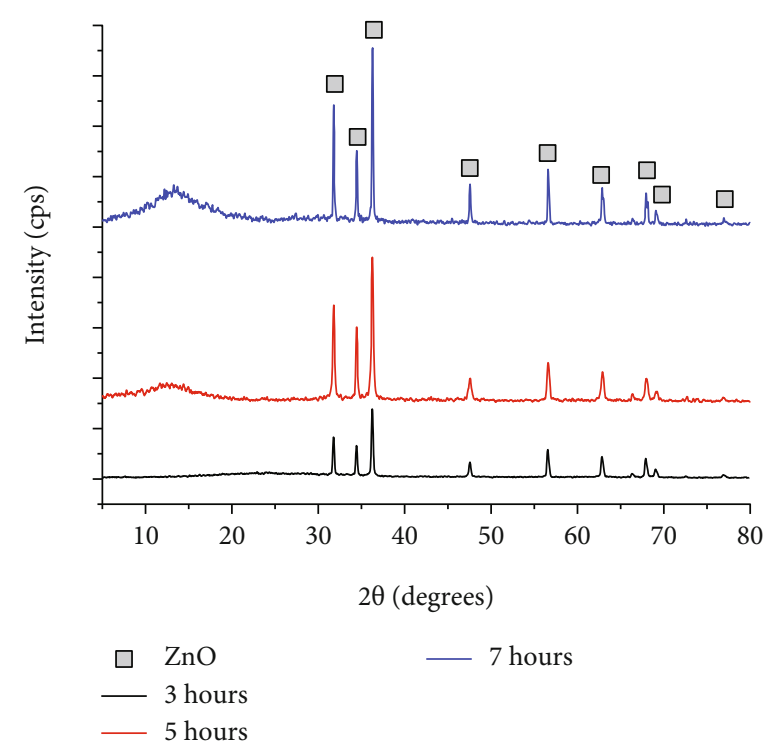

(b)

Figure 5: XRD patterns: (a) Z- $x$ - $(3 \mathrm{~h})$ samples, where $x$ is the treatment temperature of ZIF- 8 sample $\left(x=250,500\right.$, or $\left.660^{\circ} \mathrm{C}\right)$; (b) Z-660- $(y \mathrm{~h})$ samples, where $y$ is the calcination time of ZIF-8 sample ( $y=3,5$, or 7 hours).

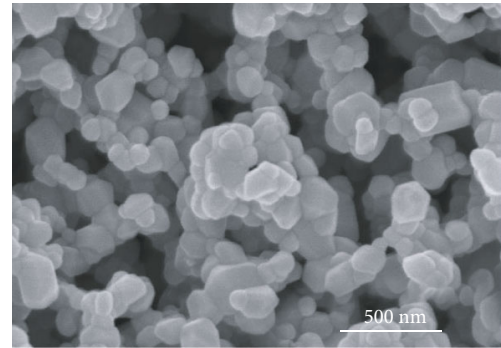

(a)

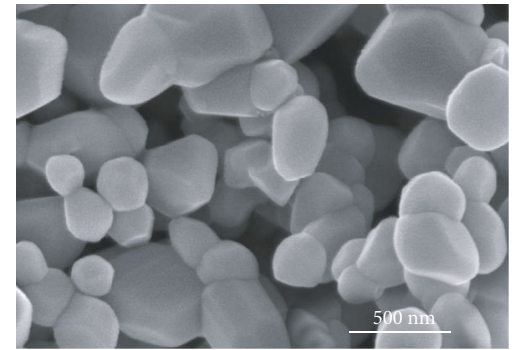

(b)

Figure 6: SEM images of $\mathrm{ZnO}$ treated at $660^{\circ} \mathrm{C}$ for $5 \mathrm{~h}(\mathrm{a})$ and $7 \mathrm{~h} \mathrm{(b).}$

and $660^{\circ} \mathrm{C}$ for 3 hours is shown in Figure 4. Figure $4(\mathrm{a})$ displays two weight losses of 61.8 and $31.1 \%$ at 226 and $332^{\circ} \mathrm{C}$, corresponding to the decomposition and combustion of meIm. Three weight losses are observed with the ZIF-8 sample (Figure $4(\mathrm{~b})$ ). The first one of about $13.6 \%$ at $87^{\circ} \mathrm{C}$ and then at $244^{\circ} \mathrm{C}$ is probably due to the removal of physically adsorbed water and the formation of 2-methylimidazole precursor bonds on the surface of the material $[46,47]$. The second weight loss of about $29.6 \%$ at $473^{\circ} \mathrm{C}$ is attributed to the decomposition of imidazole bridges in the metal-organic framework structure of ZIF-8. The third weight loss of about $17.5 \%$ at $655^{\circ} \mathrm{C}$ is ascribed to the decomposition and burning off of the remaining organic components in the material [47]. No weight losses are observed from 750 to $900^{\circ} \mathrm{C}$, indicating that pure zinc oxide is formed. Therefore, the temperatures 250,500 , and $660^{\circ} \mathrm{C}$ are selected for the thermal treatment of ZIF-8 to produce porous zinc oxide (Figure 4(c)).

The TG/dTG profiles of the Z- $x$ - $(3 \mathrm{~h})$ samples are shown in Figure 4(c). For the Z-250-(3 h) sample, only one weight loss of about $59.0 \%$ occurs at $473^{\circ} \mathrm{C}$. This loss corresponds to the breakdown of the imidazole bridges in the structure, which demonstrates that the structure of the ZIF-8 material remains stable after being treated at $250^{\circ} \mathrm{C}$. This is also evidenced on the X-ray diffraction patterns in Figure 5(a).

The X-ray diffraction of ZIF- 8 treated at $250^{\circ} \mathrm{C}$ for $3 \mathrm{~h}$ still shows peaks at the angles lower than $30^{\circ}$, typical of ZIF-8 material, and no peaks are observed at higher angles (Figure 5(a)). For the Z-500-(3 h) and Z-660-(3 h) samples, no weight losses are observed, indicating that the organic components in the material are completely decomposed, and the resulting product is zinc oxide (Figure $4(\mathrm{c})$ ). This result is also confirmed on the X-ray patterns of these two samples (Figure 5(a)), where only diffraction peaks specific to $\mathrm{ZnO}$ are present. In particular, the sample treated at $660^{\circ} \mathrm{C}$ has characteristic peaks for $\mathrm{ZnO}$ with high intensity, revealing high crystallinity and purity of the material. This crystallinity and purity might increase the photocatalytic activity of the obtained zinc oxide. Therefore, the temperature $660^{\circ} \mathrm{C}$ is chosen to investigate the influence of thermal treatment time on the structure of the resulting zinc oxide. The XRD patterns of Z-660- $(y \mathrm{~h})$ samples in Figure 5(b) show that the intensity of the specific peaks for zinc oxide increases 


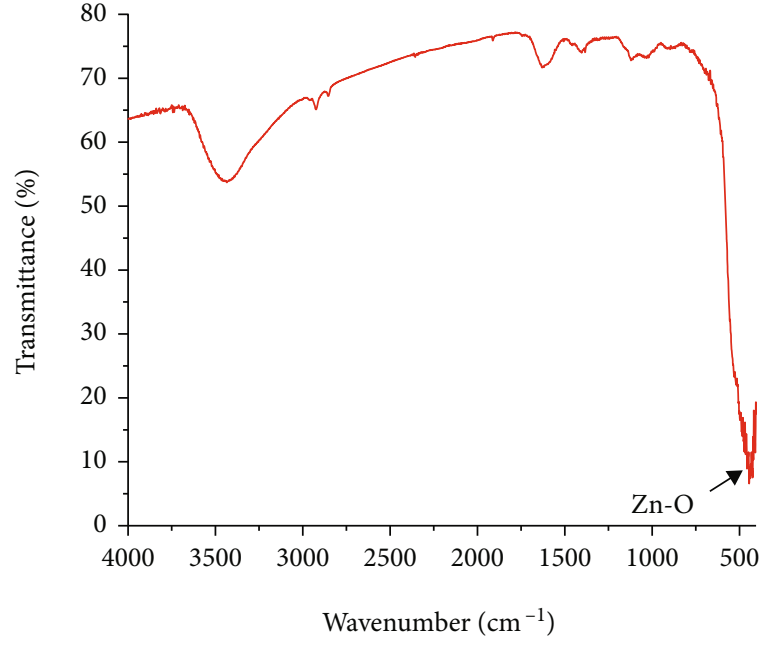

(a)

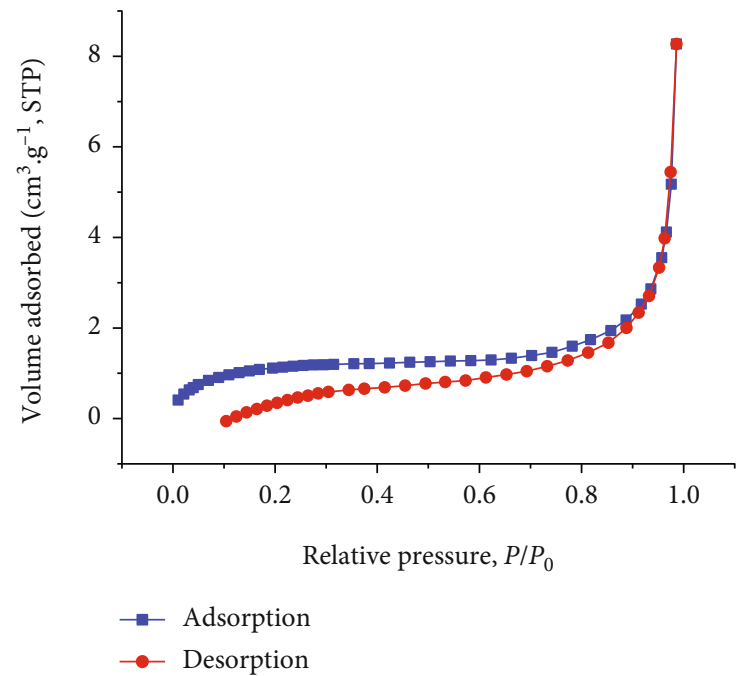

(b)

FIGURE 7: FT-IR spectrum (a) and nitrogen adsorption-desorption isotherms (b) of Z-660-(5h) sample.

significantly with the treatment time from 3 to $5 \mathrm{~h}$. However, longer treatment time does not affect the crystallinity of the material.

The SEM images indicate that the $\mathrm{ZnO}$ sample treated at $660^{\circ} \mathrm{C}$ for $5 \mathrm{~h}$ possesses particles of about $50-100 \mathrm{~nm}$ in diameter, sticking together to form pores in the material (Figure 6(a)). Meanwhile, the $\mathrm{ZnO}$ sample treated for $7 \mathrm{~h}$ sticks together to form particles with a larger diameter and lower porosity (Figure 6(b)).

As a result, the following study focuses on the Z-660-(5h) sample. As can be seen in Figure 7(a), no typical absorption bands for meIm are observed; instead, the absorption band at $400-550 \mathrm{~cm}^{-1}$ corresponding to the stretching vibration of $\mathrm{Zn}-\mathrm{O}[17,21,31]$ confirms the formation of $\mathrm{ZnO}$. This result is consistent with that of $\mathrm{X}$-ray diffraction shown in Figure 5(b). Figure 7(b) shows the isotherms of the Z-660$(5 \mathrm{~h})$ sample with strong condensation at relatively high pressure. This is the result of the condensation and evaporation of $\mathrm{N}_{2}$ in the capillaries formed among the $\mathrm{ZnO}$ particles. The specific surface area of the Z-660-(5h) sample is $4.0 \mathrm{~m}^{2} \cdot \mathrm{g}^{-1}$ (slightly lower than that reported by Du et al. on the porous $\mathrm{ZnO}$ prepared from ZIF-8, $\left.S_{\mathrm{BET}}(\mathrm{ZnO})=5.5 \mathrm{~m}^{2} \cdot \mathrm{g}^{-1}[21]\right)$.

3.3. Photocatalytic Activity of ZIF- 8 and $\mathrm{ZnO}$. Figure 8 shows that methylene blue is relatively stable under UV irradiation, and its decomposition is only $17 \%$ after $240 \mathrm{~min}$ of irradiation. In the dark, the Z-ultrasound- $(0.5 \mathrm{~h})$ sample provides only $10 \%$ of $\mathrm{MB}$ adsorption after 60 minutes, and the decomposition reaches $19 \%$ after $240 \mathrm{~min}$ of reaction. The other ZIF-8 samples also exhibit $8-10 \%$ adsorption after 60 minutes without UV irradiation. However, the decomposition of $\mathrm{MB}$ occurs rapidly with an efficiency of $58-64 \%$ after 180 minutes of the irradiation (Figure 8). This indicates that all the studied ZIF-8 samples have photocatalytic activity.

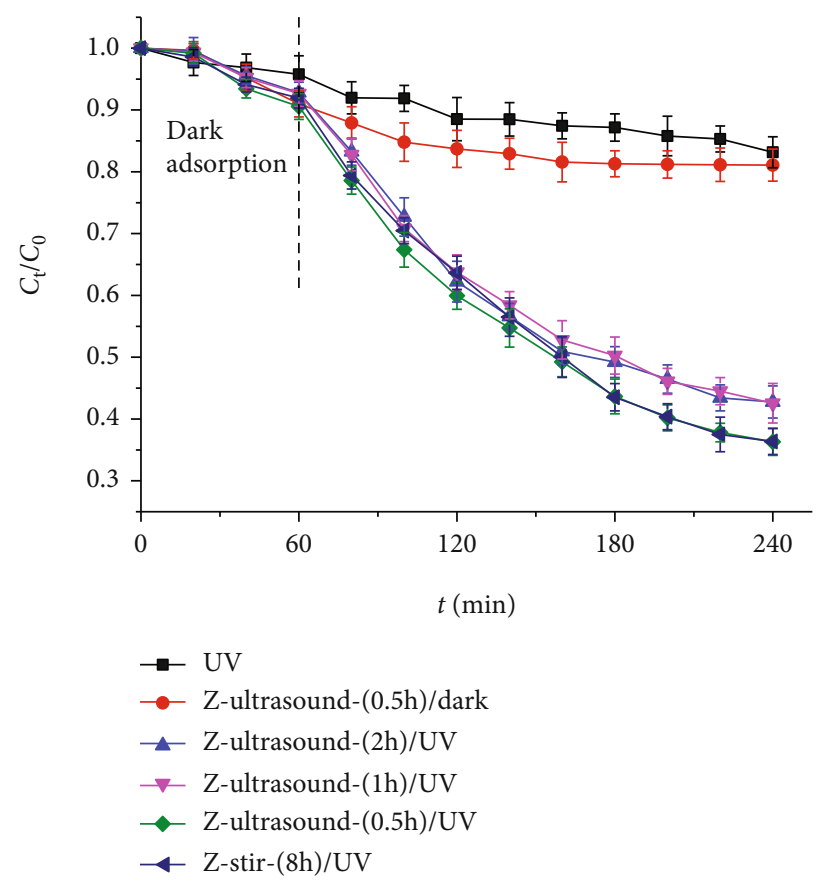

Figure 8: $\mathrm{MB}$ decomposition under different conditions (experimental conditions: ZIF-8 $0.5 \mathrm{~g} / \mathrm{L}$; MB $5 \mathrm{mg} / \mathrm{L}$; temperature $\left.30^{\circ} \mathrm{C}\right)$.

On the DR-UV-Vis spectrum, the meIm and the Z-ultrasound- $(0.5 \mathrm{~h})$ samples exhibit main absorption edges at 230 $\mathrm{nm}$ (Figure 9(a)), corresponding to the $E_{g}$ value of $5.15 \mathrm{eV}$, determined on the Kubelka-Munk plot (Figure 9(b)). Other authors $[6-8,25,34,50-52]$ also report a similar $E_{g}$ for ZIF8. In addition, the Z-ultrasound- $(0.5 \mathrm{~h})$ sample also has weak absorption bands at 303 and $415 \mathrm{~nm}$ (the inset in Figure 9(a)), corresponding to an $E_{g}$ of 3.65 and $2.55 \mathrm{eV}$ (the 


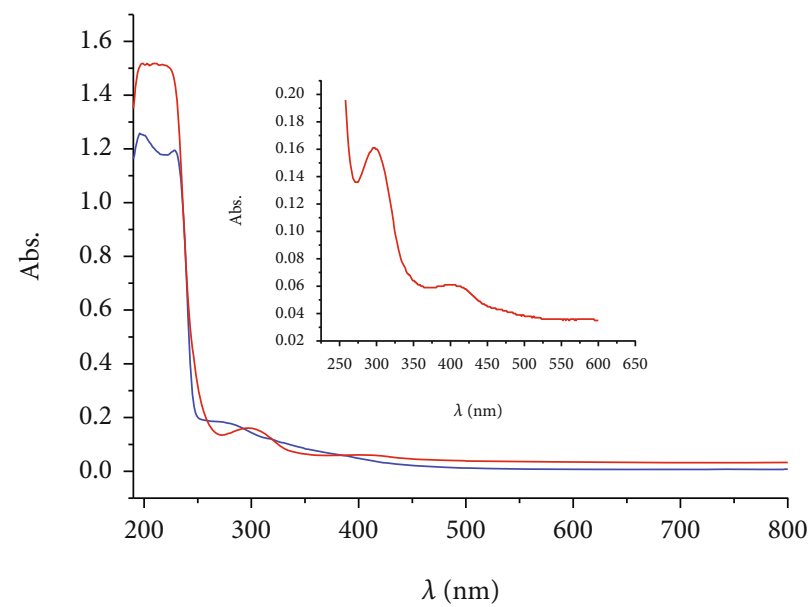

(a)

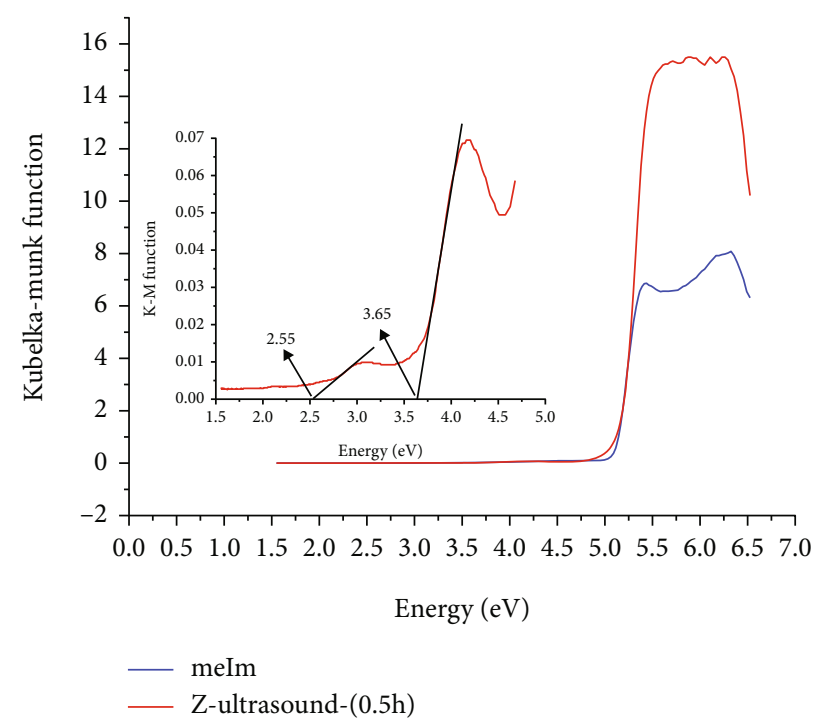

(b)

Figure 9: DR-UV-Vis spectrum (a) and the plot of Kubelka-Munk function versus the energy of absorbed light (b) of meIm and Zultrasound- $(0.5 \mathrm{~h})$.

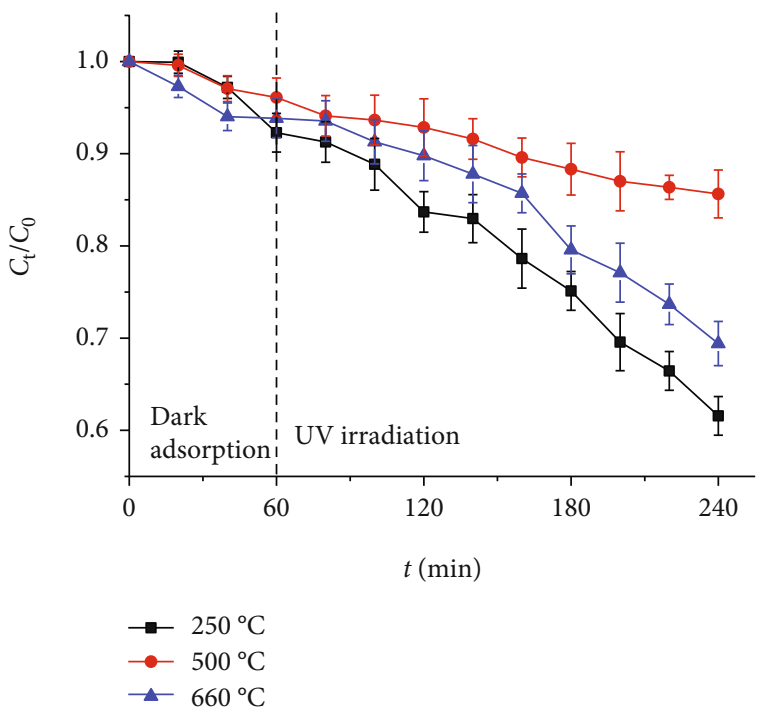

Figure 10: Photocatalytic decomposition of $\mathrm{MB}$ on Z- $x$ - $(3 \mathrm{~h})$ samples, with $x=250,500$, or $660^{\circ} \mathrm{C}$ (experimental conditions: 0.5 $\mathrm{g} / \mathrm{L}$ catalyst; $\mathrm{MB} 5 \mathrm{mg} / \mathrm{L} ; 30^{\circ} \mathrm{C}$; UV irradiation after 60 minutes).

inset in Figure 9(b)). Thanh et al. [52] also indicate that ZIF-8 has weak absorption bands corresponding to $E_{g}$ of $3.5,2.1$, and $1.8 \mathrm{eV}$. These authors suggest that this may be due to the doped centers of nitrogen. The appearance of these narrow $E_{g}$ regions explains the high photocatalytic activity of ZIF-8.

Heating temperatures also affect the structure of $\mathrm{ZnO}$ and, therefore, the decomposition efficiency of $\mathrm{MB}$ (Figure 10). Three temperatures, namely, 250, 500, and $660^{\circ} \mathrm{C}$, are used to prepare $\mathrm{ZnO}$, and all the samples have photocatalytic activity. The efficiency of $\mathrm{MB}$ decomposition on the Z-250-( $3 \mathrm{~h})$ sample is $39 \%$ after 180 minutes of the irradiation, much lower than that of ZIF-8 samples (58-

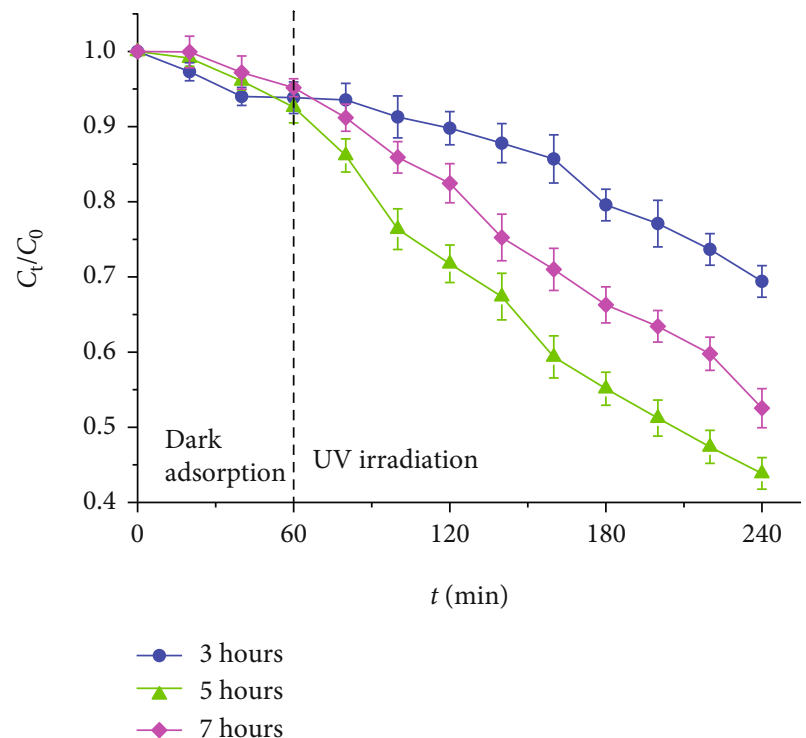

FIgUre 11: Photocatalytic decomposition of MB on Z-660- $(y \mathrm{~h})$ samples, with $y=3,5$, or 7 hours (experimental conditions: $0.5 \mathrm{~g} / \mathrm{L}$ catalyst; $\mathrm{MB} 5 \mathrm{mg} / \mathrm{L} ; 30^{\circ} \mathrm{C}, \mathrm{UV}$ irradiation after 60 minutes).

$64 \%)$, although the Z-250-( $3 \mathrm{~h})$ sample still has the structure of ZIF-8 (thermal and XRD analysis results are shown in Figures 4(c) and 5(a)). This decrease of efficiency might result from the fact that the imidazole binding components on the surface of ZIF-8 material are partly removed, and the crystallinity of the material also reduces.

Unlike the Z-250-( $3 \mathrm{~h})$ sample, the Z-500-(3h) and Z$660-(3 \mathrm{~h})$ samples possess lower catalytic activity with $15 \%$ and $31 \%$ of colour removal efficiency, respectively, after 180 minutes of the irradiation. Because, at $500-660^{\circ} \mathrm{C}$, the organic component of the metal-organic framework burns completely, the remaining product consists of only $\mathrm{ZnO}$ 


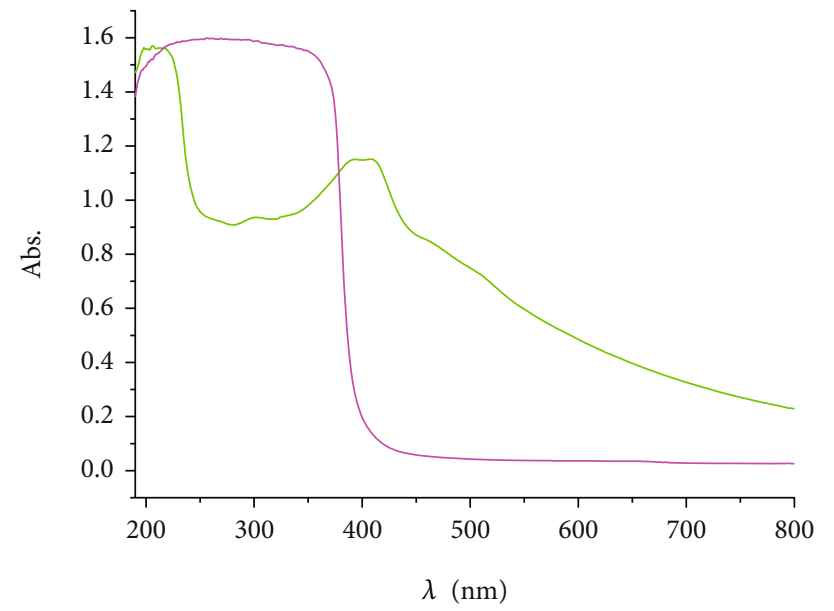

$\lambda(\mathrm{nm})$

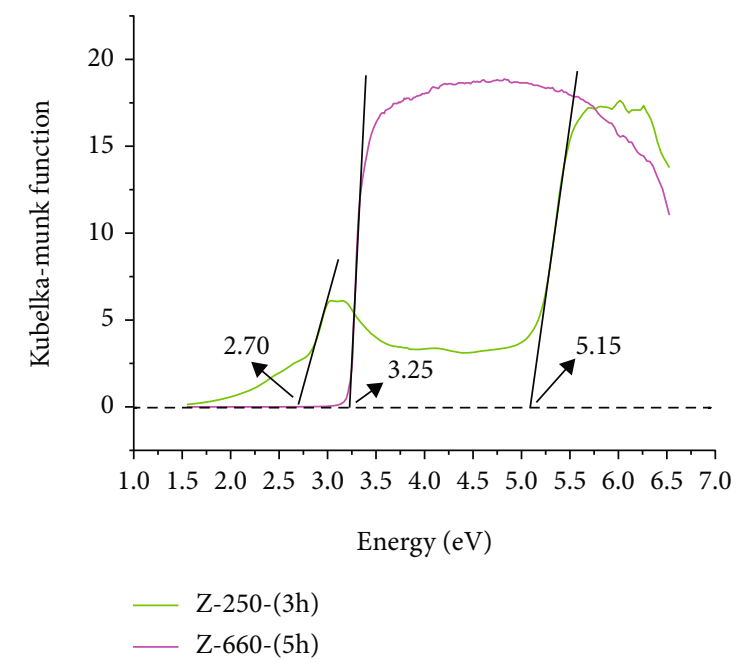

(b)

Figure 12: DR-UV-Vis spectrum (a) and the plot of Kubelka-Munk function versus the energy of absorbed light (b) of Z-250-(3 h) and Z$660-(5 \mathrm{~h})$.

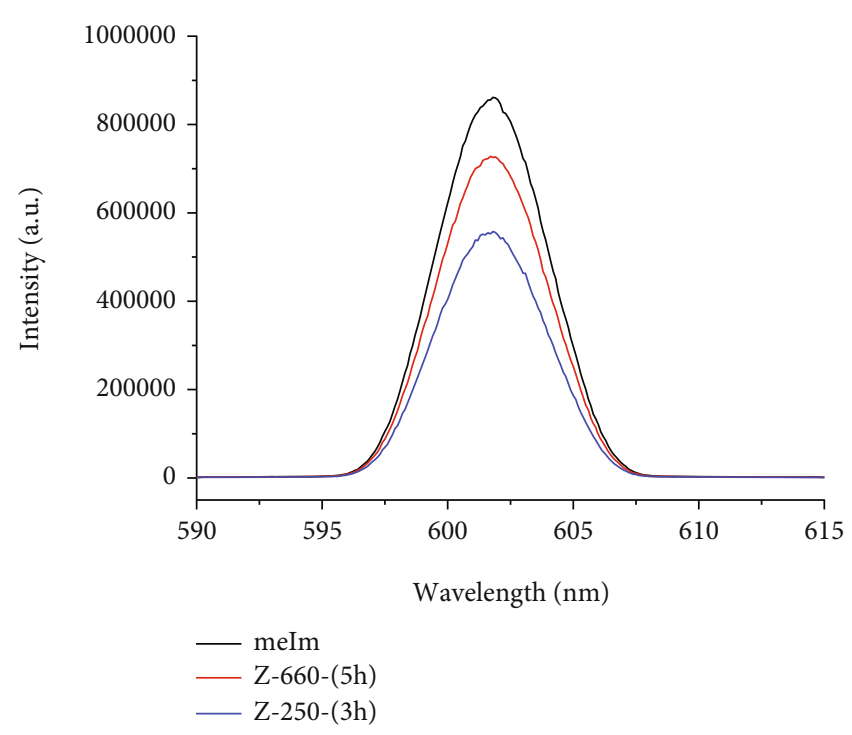

(a)

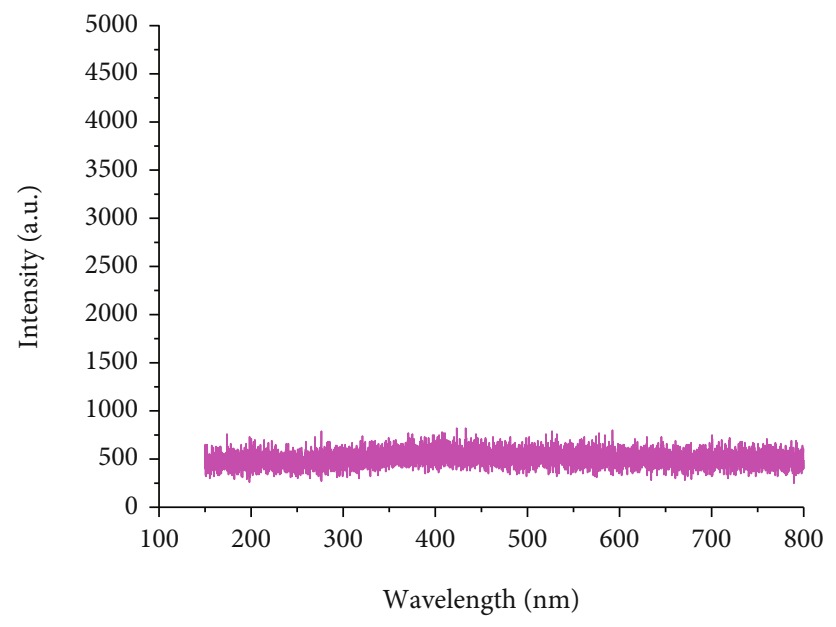

(b)

Figure 13: PL spectrum: (a) meIm, Z-660-(5 h), and Z-250-(3 h); (b) Z-ultrasound-(0.5 h).

crystals (Figure 5(a)). Thus, both these two samples should have the same photocatalytic activity.

The treatment time at $660^{\circ} \mathrm{C}$ has a significant influence on the catalytic activity of $\mathrm{ZnO}$ (Figure 11). The removal efficiency increases from $31 \%$ for the Z-660-( $3 \mathrm{~h}$ ) to $57 \%$ for the Z-660-(5h) sample. However, the Z-660-(7h) sample only reaches $48 \%$ of efficiency after 180 minutes of irradiation. The highest photocatalytic activity of the Z-660-(5 h) sample might be the result of its high crystallinity (compared with the Z-660-( $3 \mathrm{~h})$ sample) and high porosity (compared with the Z-660-(7 h) sample).

Figure 12 shows the DR-UV-Vis spectrum and the plot of Kubelka-Munk function versus the energy of absorbed light of the Z-250-(3h) and Z-660-(5h) samples. The Z-250-(3 h) sample has a main absorption edge at $230 \mathrm{~nm}$, corresponding to an $E_{g}$ of $5.15 \mathrm{eV}$, similar to the bandgap energy of the meIm bridges. In addition, this sample also has an absorption band at about $418 \mathrm{~nm}$, corresponding to an $E_{g}$ of $2.70 \mathrm{eV}$. The presence of this narrow bandgap energy explains its higher photocatalytic activity than that of the samples treated at 500 and $660^{\circ} \mathrm{C}$. For the Z-660-(5 h) sample, there is only the main absorption edge at 370 $\mathrm{nm}$, corresponding to an $E_{g}$ of $3.25 \mathrm{eV}$, similar to the $E_{g}$ of $\mathrm{ZnO}$ reported by others [23-25, 27, 31].

As can be seen that the photocatalytic activity of the Z250-(3 h) sample (Figure 10) and the Z-660-(5h) sample 
(Figure 11) is slightly lower than that of ZIF-8 (Figure 8). This result is contrary to what published by $\mathrm{Du}$ et al. [21]. This discrepancy may be due to the difference in the synthetic method. In this study, ZIF-8 is prepared in $\mathrm{MeOH}$, while in Du et al.'s report [21], ZIF-8 is synthesized in water.

The photoluminescence (PL) emission is often used to investigate the recombination of photo-excited electronhole pairs in photocatalytic materials. A high PL intensity indicates a high recombination rate, i.e., the shorter electron-hole separation time, and a low PL intensity suggests a low recombination rate and therefore a high electron-hole separation time. This is an important factor for photocatalytic reactions.

On the photoluminescence spectrum obtained at the excitation wavelength of $100 \mathrm{~nm}$, meIm (for comparison), Z-660-(5 h), and Z-250-(3 h) samples exhibit a broad emission $(595-608 \mathrm{~nm})$ with the highest intensity at $602 \mathrm{~nm}$ (Figure 13(a)). In particular, the PL emission intensity of the Z-250-(3h) sample is the lowest and significantly lower than that of meIm, indicating that the electron-hole separation time in the Z-250-( $3 \mathrm{~h})$ sample is longer, contributing to the higher photocatalytic efficiency of the Z-250- $(3 \mathrm{~h})$ sample.

Although the Z-660-(5h) sample has a higher PL emission intensity than the Z-250-(3 h) sample, it has a narrow bandgap energy $\left(E_{g}=3.25 \mathrm{eV}\right)$ and, therefore, also high photocatalytic activity. Unlike Malik et al.'s result [7] (ZIF-8 has a maximum PL intensity at $482 \mathrm{~nm}$ with excitation wavelength at $240 \mathrm{~nm}$ ) and Zheng et al.'s result [9] (ZIF-8 has a maximum PL intensity at $445 \mathrm{~nm}$ ), the PL spectrum of the Z-ultrasound- $(0.5 \mathrm{~h})$ sample in this study does not exhibit PL emission bands (Figure 13(b)). The reason for this is probably because the metal-organic framework structure of the resulting ZIF-8 material acts as electron sinks, preventing electron-hole recombination. This is because the Z-ultrasound- $(0.5 \mathrm{~h})$ sample has several $E_{g}$ values, which reduces the rate of electron-hole recombination. This result proves that ZIF-8 is a promising photocatalyst.

\section{Conclusions}

In this study, ZIF-8 material is successfully synthesized with the support of ultrasonic waves in methanol. Porous $\mathrm{ZnO}$ is also easily obtained with the thermal treatment of ZIF-8. The resulting ZIF-8 is highly crystalline and has high thermal stability at temperatures below $250^{\circ} \mathrm{C}$. Both obtained ZIF-8 and $\mathrm{ZnO}$ have photocatalytic activity for $\mathrm{MB}$ decomposition in aqueous solutions under $\mathrm{UV}$ irradiation. The $\mathrm{ZnO}$ obtained from ZIF- 8 by calcining in the air at $660^{\circ} \mathrm{C}$ for $5 \mathrm{~h}$ has high crystallinity and photocatalytic activity. However, the photocatalytic activity of ZIF-8 is slightly higher than that of $\mathrm{ZnO}$ (58-64\% as opposed to $57 \%$ ), indicating that ZIF-8 is a potential photocatalyst capable of practical application for the treatment of organic pollutants in aqueous solutions.

\section{Data Availability}

The data used to support the findings of this study are available from the corresponding author upon request.

\section{Conflicts of Interest}

The authors declare that they have no conflicts of interest.

\section{Acknowledgments}

This research was sponsored by the Thu Dau Mot University under Decision No. 260/QĐ-ĐHTDM dated 18/02/2020.

\section{References}

[1] K. S. Park, Z. Ni, A. P. Cote et al., "Exceptional chemical and thermal stability of zeolitic imidazolate frameworks," Proceedings of the National Academy of Sciences of the United States of America, vol. 103, no. 27, pp. 10186-10191, 2006.

[2] X. C. Huang, Y. Y. Lin, J. P. Zhang, and X. M. Chen, "Liganddirected strategy for zeolite-type metal-organic frameworks: zinc(II) imidazolates with unusual zeolitic topologies," Angewandte Chemie, International Edition, vol. 45, no. 10, pp. 1557-1559, 2006.

[3] L. H. Wee, T. Lescouet, J. Ethiraj et al., "Hierarchical zeolitic imidazolate framework- 8 catalyst for monoglyceride synthesis," ChemCatChem, vol. 5, pp. 3562-3566, 2013.

[4] M. Zhu, D. Srinivas, S. Bhogeswararao, P. Ratnasamy, and M. A. Carreon, "Catalytic activity of ZIF-8 in the synthesis of styrene carbonate from $\mathrm{CO}_{2}$ and styrene oxide," Catalysis Communications, vol. 32, pp. 36-40, 2013.

[5] X. Zhou, H. P. Zhang, G. Y. Wang, Z. G. Yao, Y. R. Tang, and S. S. Zheng, "Zeolitic imidazolate framework as efficient heterogeneous catalyst for the synthesis of ethyl methyl carbonate," Journal of Molecular Catalysis A: Chemical, vol. 366, pp. 43-47, 2013.

[6] H.-P. Jing, C. C. Wang, Y. W. Zhang, P. Wang, and R. Li, "Photocatalytic degradation of methylene blue in ZIF-8," RSC Advances, vol. 4, no. 97, pp. 54454-54462, 2014.

[7] A. Malik, M. Nath, S. Mohiyuddin, and G. Packirisamy, "Multifunctional CdSNPs@ZIF-8: potential antibacterial agent against GFP-expressing Escherichia coli and Staphylococcus aureusand efficient photocatalyst for degradation of methylene blue," ACS Omega, vol. 3, no. 7, pp. 8288-8308, 2018.

[8] Z. Jin and Y. Zhang, "Efficient photocatalytic hydrogen production achieved by $\mathrm{WO}_{3}$ coupled with $\mathrm{NiP}_{2}$ over ZIF-8," Catalysis Surveys from Asia, vol. 24, no. 1, pp. 59-69, 2020.

[9] W. Zheng, S. Feng, C. Shao et al., "Visible light-driven BiOI/ZIF-8 heterostructure and photocatalytic adsorption synergistic degradation of BPA," Research on Chemical Intermediates, vol. 46, no. 6, pp. 2951-2967, 2020.

[10] J. Ran, H. Chen, S. Bi et al., "One-step in-situ growth of zeolitic imidazole frameworks- 8 on cotton fabrics for photocatalysis and antimicrobial activity," Cellulose, vol. 27, no. 17, pp. 10447-10459, 2020.

[11] R. Chandra and M. Nath, "Facile synthesis of $\mathrm{ZnO}-\mathrm{SnO}_{2}$ anchored ZIF-8 nanocomposite: a potential photocatalyst," Environmental Science and Pollution Research, vol. 27, no. 20, pp. 25103-25118, 2020.

[12] Q. Wang, Y. Sun, S. Li, P. Zhang, and Q. Yao, "Synthesis and modification of ZIF-8 and its application in drug delivery and tumor therapy," RSC Advances, vol. 10, no. 62, pp. 37600-37620, 2020.

[13] M. Schelling, M. Kim, E. Otal, M. Aguirre, and J. P. Hinestroza, "Synthesis of a zinc-imidazole metal-organic framework (ZIF8) using $\mathrm{ZnO}$ rods grown on cotton fabrics as precursors: 
arsenate absorption studies," Cellulose, vol. 27, no. 11, pp. 6399-6410, 2020.

[14] M. Khabazipour and M. Anbia, "Process optimization and adsorption modeling using hierarchical ZIF-8 modified with lanthanum and copper for sulfate uptake from aqueous solution: kinetic, isotherm and thermodynamic studies," Journal of Inorganic and Organometallic Polymers and Materials, vol. 31, no. 6, pp. 2401-2424, 2021.

[15] S. Yang, Y. Wang, H. Li et al., "Synthesis of nano-ZIF-8@chitosan microspheres and its rapid removal of $p$-hydroxybenzoic acid from the agro-industry and preservatives," Journal of Porous Materials, vol. 28, no. 1, pp. 29-38, 2021.

[16] Y. Fu, M. Xin, J. Chong, R. Li, and M. Huang, "Plasmonic gold nanostars@ZIF-8 nanocomposite for the ultrasensitive detection of gaseous formaldehyde," Journal of Materials Science, vol. 56, no. 6, pp. 4151-4160, 2021.

[17] S. Feng, X. Jia, J. Yang, Y. Li, S. Wang, and H. Song, "One-pot synthesis of core-shell ZIF-8@ZnO porous nanospheres with improved ethanol gas sensing," Journal of Materials Science: Materials in Electronics, vol. 31, pp. 22534-22545, 2020.

[18] Y. Si, X. Li, G. Yang, X. Mie, and L. Ge, "Fabrication of a novel core-shell CQDs@ZIF-8 composite with enhanced photocatalytic activity," Journal of Materials Science, vol. 55, no. 27, pp. 13049-13061, 2020.

[19] C. Bae, J. Lee, L. Yao et al., "Mechanistic insight into gold nanorod transformation in nanoscale confinement of ZIF-8," Nano Research, vol. 14, no. 1, pp. 66-73, 2021.

[20] A. J. M. Reddy, N. K. Katari, P. Nagaraju, K. H. Reddy, and M. S. S. Babu, "Fabrication and deployment of nanodisc ZnO@ZIF-8, ZnO@NA and ZnO@INA cor-shell MOFs: enhanced $\mathrm{NH}_{3}$ and $\mathrm{HCHO}$ gas sensing," Journal of Materials Science: Materials in Electronics, vol. 32, no. 6, pp. 78277840, 2021.

[21] Y. Du, R. Z. Chen, J. F. Yao, and H. T. Wang, "Facile fabrication of porous $\mathrm{ZnO}$ by thermal treatment of zeolitic imidazolate framework-8 and its photocatalytic activity," Journal of Alloys and Compounds, vol. 551, pp. 125-130, 2013.

[22] M. Ahmad, E. Ahmed, Y. Zhang et al., "Preparation of highly efficient $\mathrm{Al}$-doped $\mathrm{ZnO}$ photocatalyst by combustion synthesis," Current Applied Physics, vol. 13, no. 4, pp. 697-704, 2013.

[23] L. V. Trandafilovíc, D. J. Jovanovíc, X. Zhang, S. Ptasínska, and M. D. Dramícanin, "Enhanced photocatalytic degradation of methylene blue and methyl orange by $\mathrm{ZnO}$ :Eu nanoparticles," Applied Catalysis B: Environmental, vol. 203, pp. 740-752, 2017.

[24] J. E. Lee, N. T. Khoa, S. W. Kim, E. J. Kim, and S. H. Hahn, "Fabrication of $\mathrm{Au} / \mathrm{GO} / \mathrm{ZnO}$ composite nanostructures with excellent photocatalytic performance," Materials Chemistry and Physics, vol. 164, pp. 29-35, 2015.

[25] H. Kim, W. Kim, J. Park et al., "Surface conversion of $\mathrm{ZnO}$ nanorods to ZIF-8 to suppress surface defects for a visibleblind UV photodetector," Nanoscale, vol. 10, no. 45, pp. 21168-21177, 2018.

[26] J. Cui, L. Wang, Y. Han et al., "ZnO nano-cages derived from ZIF-8 with enhanced anti mycobacterium-tuberculosis activities," Journal of Alloys and Compounds, vol. 766, pp. 619$625,2018$.

[27] K. G. Chandrappa and T. V. Venkatesha, "Electrochemical synthesis and photocatalytic property of zinc oxide nanoparticles," Nano-Micro Letters, vol. 4, no. 1, pp. 14-24, 2012.

[28] D. P. Wu, X. L. Wang, K. Cao et al., "ZnO nanorods with tunable aspect ratios deriving from oriented-attachment for enhanced performance in quantum-dot sensitized solar cells," Electrochimica Acta, vol. 231, pp. 1-12, 2017.

[29] Q. Wan, Q. H. Li, Y. J. Chen et al., "Fabrication and ethanol sensing characteristics of $\mathrm{ZnO}$ nanowire gas sensors," Applied Physics Letters, vol. 84, no. 18, pp. 3654-3656, 2004.

[30] J. Jiang, J. Pi, and J. Cai, "The advancing of zinc oxide nanoparticles for biomedical applications," Bioinorganic Chemistry and Applications, vol. 2018, Article ID 1062562, 18 pages, 2018.

[31] R. Jagadish, S. Yellappa, M. Mahanthappa, and K. B. Chandrasekhar, "Zinc oxide nanoparticle-modified glassy carbon electrode as a highly sensitive electrochemical sensor for the detection of caffeine," Journal of the Chinese Chemical Society, vol. 64, no. 7, pp. 813-821, 2017.

[32] R. Vittal and K.-C. Ho, "Zinc oxide based dye-sensitized solar cells: a review," Renewable and Sustainable Energy Reviews, vol. 70, pp. 920-935, 2017.

[33] H. D. Mai, K. Rafiq, and H. Yoo, "Nano metal-organic framework-derived inorganic hybrid nanomaterials: synthetic strategies and applications," Chemistry - A European Journal, vol. 23, no. 24, pp. 5631-5651, 2017.

[34] X. Yang, Z. Wen, Z. Wu, and X. Luo, "Synthesis of ZnO/ZIF-8 hybrid photocatalysts derived from ZIF-8 with enhanced photocatalytic activity," Inorganic Chemistry Frontiers, vol. 5, no. 3, pp. 687-693, 2018.

[35] J. Cravillon, S. Munzer, S.-J. Lohmeier, A. Feldhoff, K. Huber, and M. Wiebcke, "Rapid room-temperature synthesis and characterization of nanocrystals of a prototypical zeolitic imidazolate framework," Chemistry of Materials, vol. 21, no. 8, pp. 1410-1412, 2009.

[36] H. Bux, F. Liang, Y. Li, J. Cravillon, M. Wiebcke, and J. Caro, "Zeolitic imidazolate framework membrane with molecular sieving properties by microwave-assisted solvothermal synthesis," Journal of the American Chemical Society, vol. 131, pp. 1600-16001, 2009.

[37] H. Bux, A. Feldhoff, J. Cravillon, M. Wiebcke, Y. S. Li, and J. Caro, "Oriented zeolitic imidazolate framework-8 membrane with sharp H2/C3H8 molecular sieve separation," Chemistry of Materials, vol. 23, no. 8, pp. 2262-2269, 2011.

[38] M. C. McCarthy, V. Varela-Guerrero, G. V. Barnett, and H. K. Jeong, "Synthesis of zeolitic imidazolate framework films and membranes with controlled microstructures," Langmuir, vol. 26, no. 18, pp. 14636-14641, 2010.

[39] S. R. Venna and M. A. Carreon, "Highly permeable zeolite imidazolate framework- 8 membranes for $\mathrm{CO}_{2} / \mathrm{CH}_{4}$ separation," Journal of the American Chemical Society, vol. 132, no. 1, pp. 76-78, 2010.

[40] F. Hillman, J. M. Zimmerman, S. M. Paek, M. R. A. Hamid, W. T. Lim, and H. K. Jeong, "Rapid microwave-assisted synthesis of hybrid zeolitic-imidazolate frameworks with mixed metals and mixed linkers," Journal of Materials Chemistry A, vol. 5, no. 13, pp. 6090-6099, 2017.

[41] T. V. Tran, H. Nguyen, P. H. A. Le et al., "Microwave-assisted solvothermal fabrication of hybrid zeolitic-imidazolate framework (ZIF-8) for optimizing dyes adsorption efficiency using response surface methodology," Journal of Environmental Chemical Engineering, vol. 8, no. 4, p. 104189, 2020.

[42] W. Sun, X. Zhai, and L. Zhao, "Synthesis of ZIF-8 and ZIF-67 nanocrystals with well-controllable size distribution through reverse microemulsions," Chemical Engineering Journal, vol. 289, pp. 59-64, 2016. 
[43] B. Shen, B. Wang, L. Zhu, and L. Jiang, "Properties of cobaltand nickel-doped ZIF- 8 framework materials and their application in heavy-metal removal from wastewater," Nanomaterials, vol. 10, no. 9, p. 1636, 2020.

[44] P. D. du, N. V. Duy Thanh, and N. T. Hieu, "Evaluation of structural properties and catalytic activities in Knoevenagel condensation reaction of zeolitic imidazolate framework-8 synthesized under different conditions," Advances in Materials Science and Engineering, vol. 2019, Article ID 6707143, 8 pages, 2019.

[45] M. Zhu, S. R. Venna, J. B. Jasinski, and M. A. Carreon, "Roomtemperature synthesis of ZIF-8: the coexistence of $\mathrm{ZnO}$ nanoneedles," Chemistry of Materials, vol. 23, no. 16, pp. 35903592, 2011.

[46] J. Yao, R. Chen, K. Wang, and H. Wang, "Direct synthesis of zeolitic imidazolate framework-8/chitosan composites in chitosan hydrogels," Microporous and Mesoporous Materials, vol. 165, pp. 200-204, 2013.

[47] M. G. F. Rodrigues, T. L. A. Barbosa, and D. P. A. Rodrigues, "Zinc imidazolate framework-8 nanoparticle application in oil removal from oil/water emulsion and reuse," Journal of Nanoparticle Research, vol. 22, no. 11, p. 328, 2020.

[48] M. Anisi, A. A. Ghoreyshi, E. Mehrvarz, and A. Rahimpour, "Synthesize optimization, characterization, and application of ZIF-8 adsorbent for elimination of olive oil from aqueous solution," Environmental Science and Pollution Research, vol. 28, no. 10, pp. 12725-12739, 2021.

[49] Y. Zhang, Y. Jia, M. Li, and L. Hou, "Influence of the 2-methylimidazole/zinc nitrate hexahydrate molar ratio on the synthesis of zeolitic imidazolate framework- 8 crystals at room temperature," Scientific Reports, vol. 8, 2018.

[50] A. Schejn, A. Aboulaich, L. Balan et al., " $\mathrm{Cu}^{2+}$-doped zeolitic imidazolate frameworks (ZIF-8): efficient and stable catalysts for cycloadditions and condensation reactions," Catalysis Science \& Technology, vol. 5, no. 3, pp. 1829-1839, 2015.

[51] R. Chandra and M. Nath, "Multi-core-shell TiO2 NPs@ZIF-8 composite for enhanced photocatalytic degradation and adsorption of methylene blue and rhodamine-B," Chemistry Select, vol. 2, pp. 7711-7722, 2017.

[52] M. T. Thanh, T. V. Thien, P. D. Du, N. P. Hung, and D. Q. Khieu, "Iron doped zeolitic imidazolate framework (Fe-ZIF8): synthesis and photocatalytic degradation of RDB dye in Fe-ZIF-8," Journal of Porous Materials, vol. 25, no. 3, pp. 857-869, 2018. 